\title{
Thermal Storage and Advanced Heat Transfer Fluids
}

We evaluate the properties of fluids that transfer and store heat in concentrating solar power (CSP) plants to improve the thermal-to-electricity efficiency and lower the operational cost of the plants.

Traditionally, CSP plants have used synthetic oils as heat transfer fluids and molten salts for thermal energy storage. At the National Renewable Energy Laboratory (NREL), we are improving these materials as well as developing and characterizing advanced nanofluids and phase-change materials (PCMs) for thermal storage applications.

Our capabilities in thermal storage and advanced heat transfer fluids center primarily around the following three areas:

\section{Measuring Thermophysical Properties}

In our Thermal Storage Materials Laboratory, we use a variety of instruments to measure the thermophysical properties of heat transfer fluids and storage materials to predict both the behavior of the materials in a storage system and the overall performance of the system.

The facility functions as an analytical laboratory, supporting a wide variety of materials research for NREL and its university and industry partners.

We use a range of instruments-including a differential scanning calorimeter, thermal gravimetric analyzer, rheometer, high-precision balance, and oven-to measure the melting point, boiling point, heat capacity, density, viscosity, and phasetransition enthalpies for storage materials at temperatures from ambient to $600^{\circ} \mathrm{C}$. For measuring thermal conductivity, we are

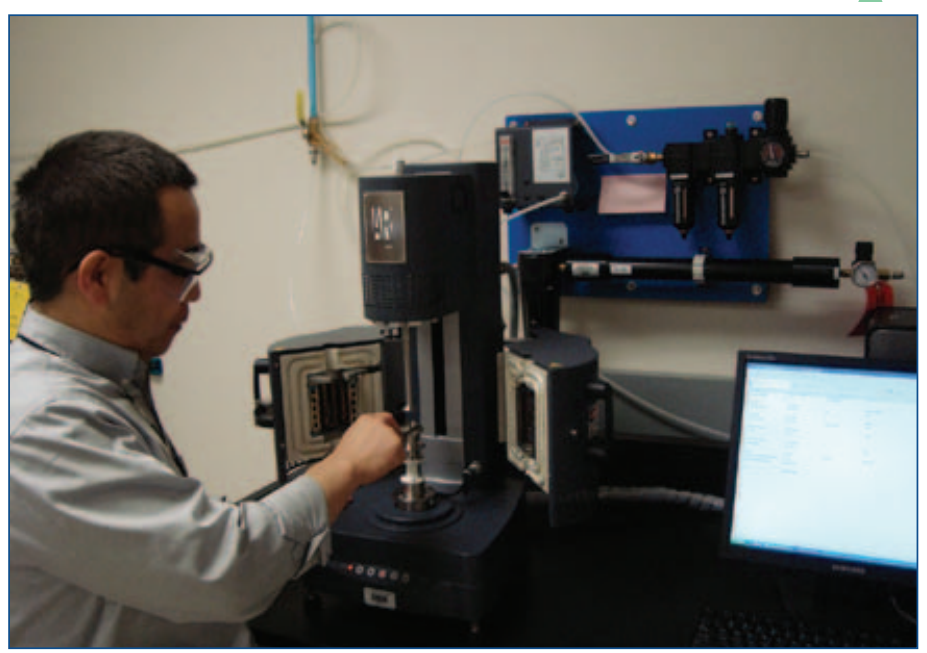

An NREL scientist in the new Thermal Storage Materials Laboratory uses a rheometer to measure fluid viscosity as part of his work to characterize new heat transfer fluids for CSP plants. designing and building an instrument based on the transient hot-wire method.

We measure the thermophysical properties of known and new heat transfer materials, as well as phase-change materials. By determining the thermal properties, we can identify those materials that will increase thermal storage capacity, thermodynamic efficiency, and dispatchability-as well as lower the levelized cost of energy_of a CSP plant.

\section{Measuring Fluid Flow and Heat Transfer}

Our Thermal Storage Process and Components Laboratory is being established as a testing lab with the equipment and accessories needed to measure the fluid flow and heat transfer behavior/performance of process components of storage systems-complete with oil, steam, and salt heat transfer fluids. Such an evaluation of process unit operations is essential for determining the overall performance of a complete thermal storage system. We will use test results to evaluate potential storage systems before they are tested at full scale.

The facility will encompass roughly 1,500 square feet and will be equipped with about 100 kilowatts of electrical heating and chilling. It will include data acquisition and control instrumentation to monitor and control process components during testing.

In the testing process, data will be collected over a period of time sufficient to cover many temperature cycles of thermal charge and discharge. The data will include measures of maximum storage capacity, plus charge and discharge rates over time. By analyzing these data, our researchers will determine if the system is able to function consistently with high performance. 


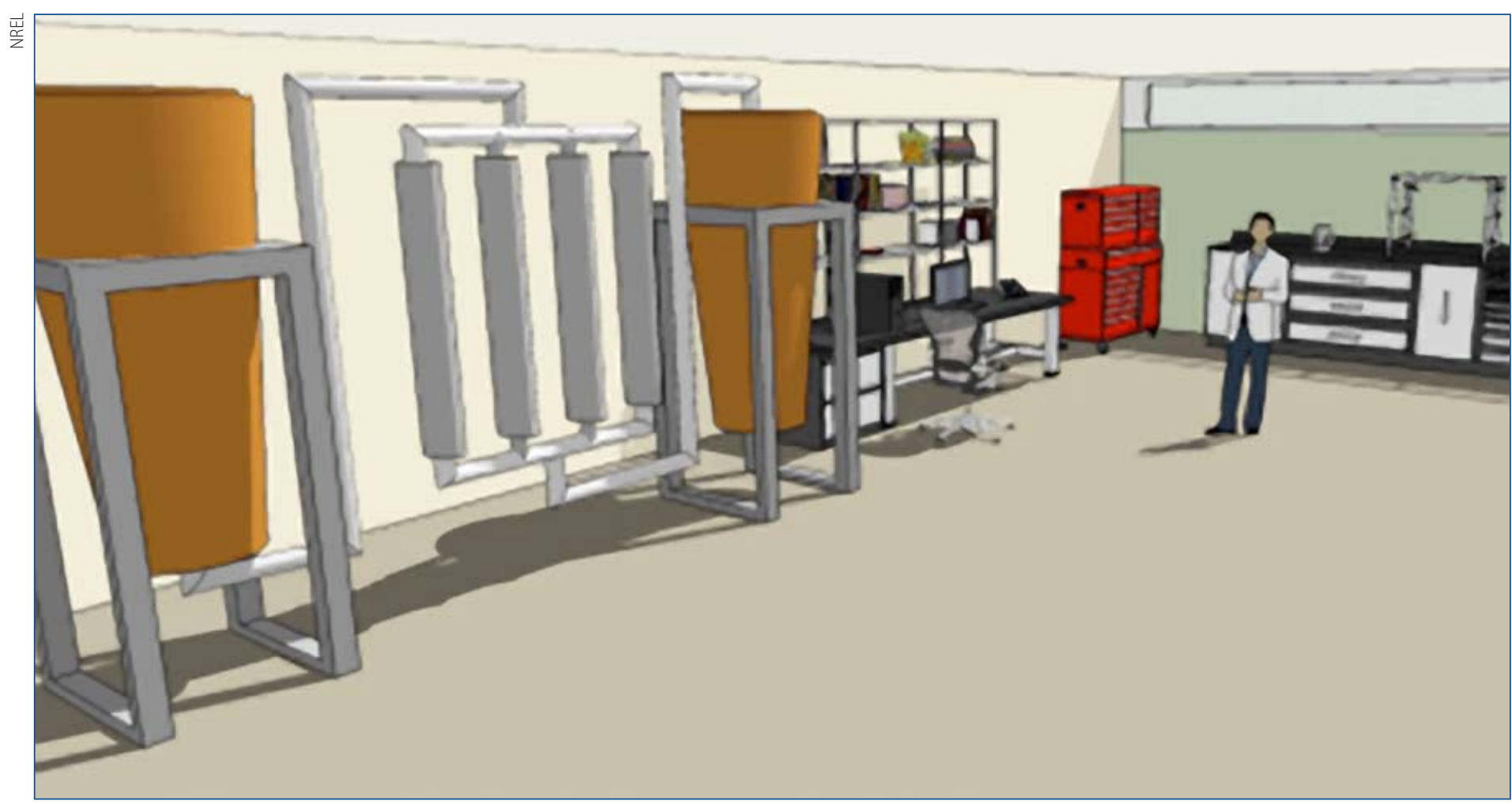

The Thermal Storage Process and Components Laboratory will operate in a temporary location while its permanent home, illustrated here, is developed on the NREL campus. Initial testing in the lab may relate to storing the thermal energy content of steam and will include the use of phase-change materials.

\section{Simulating Flow of Thermal Energy and Fluid}

At NREL, we use thermal-storage heat-transfer and fluidflow modeling to simulate the flow of thermal energy and fluid over time in complex geometries such as tanks, piping, and packed beds. Over a relatively short period of time, the techniques can help to predict the performance of complex heat transfer and flow systems-without constructing a physical system.

Specially trained staff who understand the mathematical basis for modeling set up simulations using computer simulation software, such as FLUENT, and associated hardware. The software code solves a set of mathematical equations that represent energy and material balances.

For each simulation, the results are a set of temperatures, pressures, and fluid-flow velocity maps that specify the conditions for a particular geometry and period of simulation time. The information helps us to evaluate sensitivities that result from changes in storage system design and the resulting impact on CSP power plant performance and cost.

Contact Greg Glatzmaier, Greg.Glatzmaier@nrel.gov, 303-384-7470.

\section{National Renewable Energy Laboratory}

1617 Cole Boulevard, Golden, Colorado 80401

303-275-3000 - www.nrel.gov

Printed with a renewable-source ink on paper containing at least $50 \%$ wastepaper, including $10 \%$ post consumer waste.

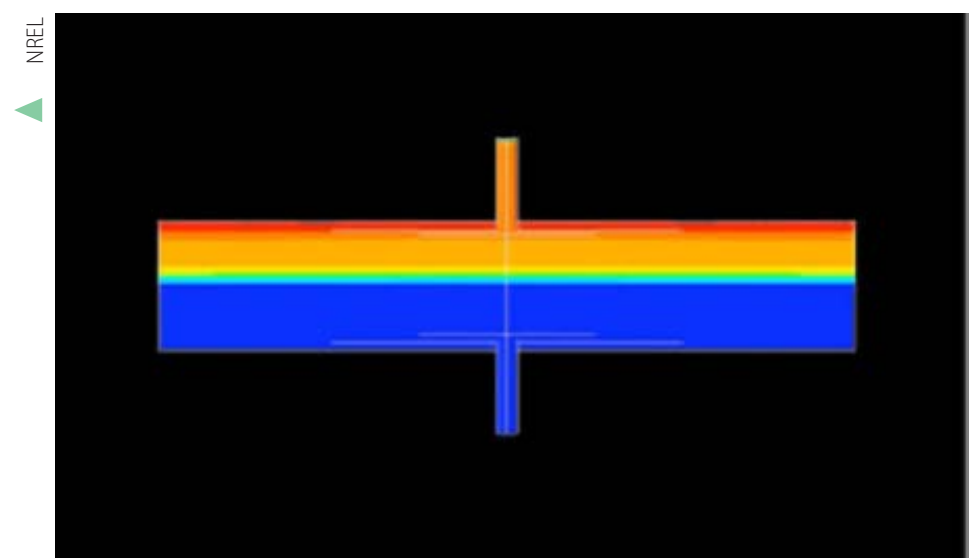

This graphic shows computer modeling results for a thermocline storage system, which stores thermal energy in a single vessel that contains a stationary filler material. The system has hot (top) and cold (bottom) regions, separated by a sharp temperature partition or "thermocline." The system's behavior is highly dependent on the properties of the filler material and the fluid that flows through it. Modeling these systems provides a wealth of information about their operation and performance without actually constructing a physical system.
NREL is a national laboratory of the U.S. Department of Energy Office of Energy Efficiency and Renewable Energy Operated by the Alliance for Sustainable Energy, LLC

NREL/FS-550-48660 • August 2010 